\title{
Unusual occurrence of dextrocardia with situs inversus in succeeding generations of a family
}

\author{
PREM CHIB, D. N. GROVER, AND B. N. SHAHI \\ From the Department of Medicine, Armed Forces Medical College, Pune, India
}

SUMMARY In three cases of dextrocardia with situs inversus affecting a father and his two sons, the father had married his first cousin, the daughter of his father's sister, so that the two sons were the products of a consanguineous marriage. The general and familial incidence of the condition and the genetic influences responsible for it are discussed.

Dextrocardia is said to have been seen in animals in the fourth century $\mathrm{BC}$ and was first described in man in AD 1600 by Fabricius (Keith et al, 1958). In 1643 the anatomist Marcus Aurelius Severinus identified dextrocardia with complete situs inversus (Brown, 1950). Since then innumerable cases have been described and various classifications of the condition exists, the most comprehensive being that of Van Praagh et al. (1964) in which eight anatomical subtypes have been distinguished.

Dextrocardia with complete situs inversus is usually discovered incidentally in otherwise normal subjects (Torgersen, 1949; McGaff et al, 1963). The familial incidence is rarer than in the general population (Mital et al, 1974). The factors responsible for situs inversus are obscure and a high incidence of consanguinity among the parents of affected sibships has been reported (Cockayne, 1938). Familial cases have almost always been confined to sibships, suggesting an autosomal recessive trait (Cockayne, 1938). Situs inversus in more than one generation of the same family is extremely rare. Warkany (1971) cites only six such instances and suggests the transmission as a dominant trait in these cases. The present report deals with three cases of dextrocardia with situs inversus occurring in two generations of a family.

\section{Case reports}

Case 1 A 24-year-old man developed an influenzalike illness for which he sought medical advice. Examination revealed the apex beat on the right side of his chest and a palpable liver in the left hypochrondrium. The electrocardiogram showed the typical Received for publication 26 March 1976 pattern of dextrocardia. Chest $x$-ray examination showed a right-sided heart, and barium meal examination showed stomach, descending colon, and sigmoid colon on the right side. Radiologically the frontal sinuses were normally developed, there was no evidence of bronchiectasis or of any other congenital heart disease or congenital abnormality such as spina bifida, hydrocephaly, etc.

Case 2 A 20-year-old man, the brother of the first patient, was found to have a right-sided apex beat, and an electrocardiogram showed the characteristic pattern of dextrocardia (Fig. 1). Chest $x$-ray examination and barium meal examination showed complete inversion of the viscera (Fig. 2).

Case 3 A 52-year-old man, father of the first two patients. After finding situs inversus in the two brothers we examined their parents (there were no other sibs). The parents were first cousins, since the father had married the daughter of his father's sister. The mother was normal. The father had dextrocardia with situs inversus. This was confirmed electrocardiographically and by radiological examination, which showed a right-sided heart and stomach.

\section{Discussion}

Mirror-image dextrocardia with situs inversus occurs in from 1 in 10000 to 1 in 5000 of the general population (Lev et al., 1968; Mital et al., 1974). The incidence among cases of established congenital heart disease is much higher (Torgersen, 1949; Lev et al., 1968). The condition is most often found incidentally in an individual whose heart is otherwise normal 


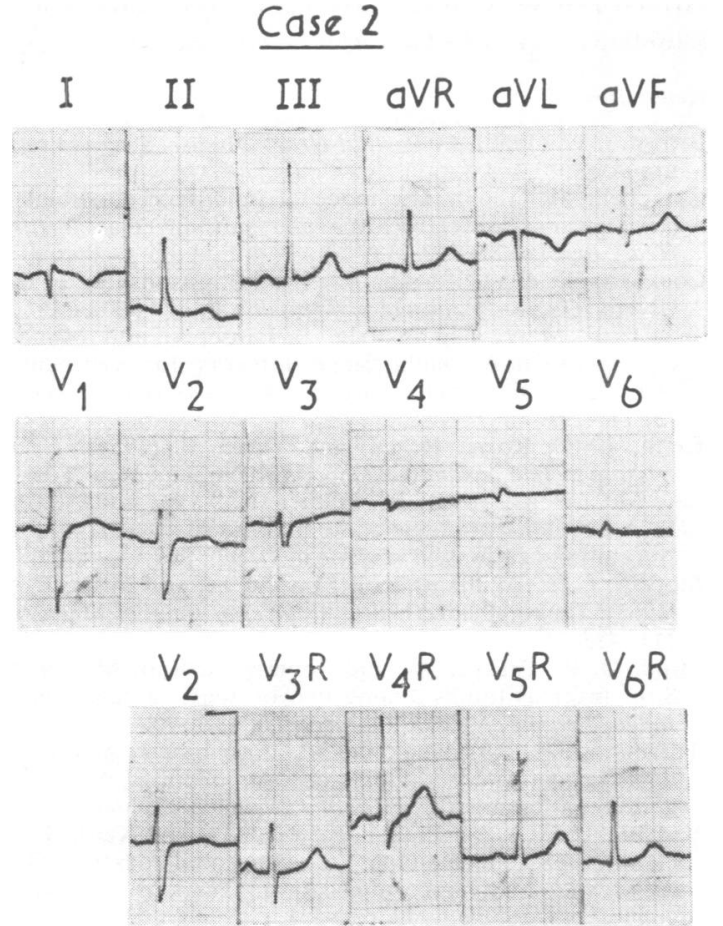

Fig. 1 Case 2. Electrocardiogram showing pattern of dextrocardia.

(Torgersen, 1949; McGaff et al., 1963). The incidence of congenital heart disease, however, is higher in persons with dextrocardia and situs inversus than in persons with the normal situs solitus. Just as dextrocardia with situs inversus is merely a mirror image of the normal situs solitus, so also any associated cardiac malformations are usually mirror images of similar malformations in persons with the normal situs solitus (Torgersen, 1949). In isolated dextrocardia, in which the heart is on the right side without inversion of the abdominal viscera, malformations of the heart are almost invariably present (Torgersen, 1949).

The factors responsible for situs inversus are not clear (Lev et al., 1968). de la Cruz et al. (1967) proposed the theory that the planes of symmetry are established quite early in the development of the embryo. Right and left halves are endowed with peculiar potentialities which differentiate them from each other. These halves may be normally placed (situs solitus) or inverted (situs inversus). Since the basic factors governing the potentialities responsible for the normal situs solitus are not known, so the nature of the disturbance of such factors in situs inversus has yet to be elucidated.

Situs inversus has been produced experimentally in mammals by $X$-irradiation and the injection of trypan blue in the early weeks of gestation (Warkany, 1971). Cockayne (1938) cited several sibships with more than one affected member but with normal parents. He found also that a high percentage of marriages of first cousins resulted in visceral transposition in more than one affected offspring (6 in 52 consecutive fraternities). He believed that complete transposition of the viscera is inherited through a single autosomal recessive gene. However, Torgersen (1949), in his radiological survey of one million persons in Norway, found no evidence to support either the single recessive gene theory or that consanguinity
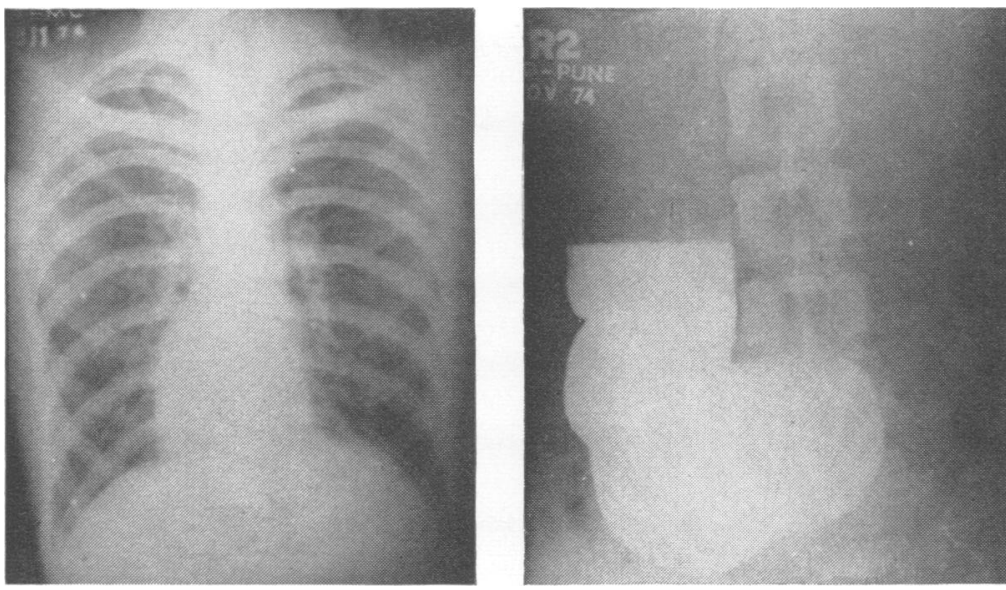

Fig. 2 Case 2. X-ray pictures showing right-sided heart and stomach. 
was responsible for familial cases. Campbell (1963) has reviewed the published reports and clarified the mode of inheritance. He studied 21 sibs of 10 families with situs inversus, and found one case each in first and second cousins. Whereas Cockayne (1938) was able to cite only one proved instance in which two generations of a family were affected, by 1971 at least six instances had been reported (Warkany, 1971), suggesting that in a few cases at least a dominant trait may be responsible for the transmission.

The present case report is remarkable for a number of reasons. Firstly, three cases of dextrocardia with situs inversus are described in a single family. Secondly, two succeeding generations of the family are affected, with one case in the first and two in the second generation. Moreover, the two cases of the second generation (that is, the two sibs, cases 1 and 2) were the products of a consanguineous mating of which one partner (case 3) was himself affected. It was not possible to explore further the genealogy of these cases as no other relatives were available for examination.

We thank Lt-General R. S. Hoon, Chief Consultant (Medicine), Office of the Director General Armed Forces Medical Services, New Delhi, India, for reviewing and correcting this paper. We also thank Maj-General B. D. P. Rao, Commandant, and Brigadier J. C. Chatterji, Professor of Medicine,
Armed Forces Medical College, for their advice and guidance.

\section{References}

Brown, J. W. (1950). Congenital Heart Disease. Staples Press, London.

Campbell, M. (1963). The mode of inheritance in isolated laevocardia and dextrocardia and situs inversus. British Heart Journal, 25, 803-813.

Cockayne, E. A. (1938). The genetics of transposition of the viscera. Quarterly Journal of Medicine, 7, 479-493.

de la Cruz, M. V., Espino-Vala, J., Fause, A., and Munoz, C. L. (1967). An embryological theory for ventricular inversions and their classification. American Heart Journal, 73, 777-793.

Keith, J. D., Rowe, R. D., and Valad, P. (1958). Heart Disease in Infancy and Childhood. Macmillan, New York.

Lev, M., Liberthson, R. R., Eckner, F. A. O., and Arcilla, R. A. (1968). Pathologic anatomy of dextrocardia and its clinical implications. Circulation, 37, 979-999.

McGaff, C. L., Williams, J. B., Leight, L., and Little, J. A. (1963). The right sided heart. Archives of Internal Medicine, 111, 483-487.

Mital, O. P., Prasad, R., and Someswara Rao, M. (1974). Situs inversus totalis among two brothers: a case report. Indian Journal of Chest Diseases, 16, 188-190.

Torgersen, J. (1949). Genic factors in asymmetry and in the development and pathologic changes of lungs, heart and abdominal organs. Archives of Pathology, 47, 566-593.

Van Praagh, R., Van Praagh, S., Vlad, P., and Keith, J. D. (1964). Anatomical types of congenital dextrocardia: diagnostic and embryological implications. American Journal of Cardiology, 13, 510-531.

Warkany, J. (1971). Congenital Malformations. Year Book Medical Publishers, Chicago. 